Article

\title{
Photocatalytic Transformation of Triclosan. Reaction Products and Kinetics
}

\author{
Sophie Schröder, $\mathbf{M}^{\mathrm{a}}$-Fresnedo San-Román * and Inmaculada Ortiz \\ Departamento de Ingenierías Química y Biomolecular, ETSIIyT, Universidad de Cantabria, Avda. de los Castros, \\ 39005 Santander, Spain; schrodersm@unican.es (S.S.); ortizi@unican.es (I.O.) \\ * Correspondence: sanromm@unican.es
}

Received: 20 November 2020; Accepted: 14 December 2020; Published: 16 December 2020

check for updates

\begin{abstract}
Chloro-2-[2,4-dichlorophenoxy]-phenol, or triclosan (TCS), is an antimicrobial and antifungal agent with high resistance to conventional wastewater treatments, thus, more effective remediation technologies are necessary, where photocatalytic processes deserve special attention due to the high degradation rates of TCS, and the use of a renewable source of energy. However, different by-products may be formed during the treatment, sometimes more harmful than the parent compounds. Efforts to detail reaction pathways continually feed into related literature; however, knowing the transformation kinetics and the dependence on the operating variables is essential for the correct design of the abovementioned remediation technologies. This work contributes to increasing the knowledge necessary for the application of photocatalytic processes for the degradation of emerging pollutants, with TCS as a case study. First, an experimental plan to analyze the influence of the operating variables was carried out, determining time courses of the parent and intermediate compounds. Next, the kinetic model and parameters that are capable of predicting TCS concentration and its derivatives as a function of the operating conditions are provided. This constitutes a very useful tool to predict the performance of wastewater remediation treatment both in the degradation of the original pollutant and in the reduction of the toxicity in the treated water.
\end{abstract}

Keywords: emerging pollutants; triclosan; photocatalytic process; intermediate derivatives; kinetic modeling

\section{Introduction}

Over the past decades, the world population has experienced significant growth, resulting in the increase in domestic and industrial activities that have, as a consequence, a great increment in the consumption of freshwater. This leads to a rise in the discharge of wastewaters containing a variety of unregulated pollutants, causing disastrous effects in the environment [1]. Urban wastewaters contain increasing concentrations of pharmaceutical and personal care products (PPCPs), characterized by their broad use, with a steady and daily increase. 5-Chloro-2-[2,4-dichlorophenoxy]-phenol, better known as triclosan (TCS), belongs to this group; it is used as an antimicrobial and antifungal agent and is present in different consumer goods (toothpaste, hand wash, hand sanitizers, toys, etc.) [2]. TCS is resistant to biodegradation and is environmentally persistent; it presents severe toxicity and relatively high lipophilicity [3,4]. This substance can remain in the environment for a long time and can be retained in sediments [5], sewage sludge [6] or indoor dust [7,8]. Moreover, it has been detected in the influent [9] and even in the effluent [10,11] of various municipal wastewater treatment plants (WWTPs), because of the low effectiveness of conventional wastewater treatments [12-14]. As a result, it has been found both in natural and drinking water $[15,16]$. Consequently, TCS ends up in aquatic organisms, which belong to the basic diet for human beings, finally entering the human body, e.g., tissues, skin, and it has even been detected in human breast milk $[17,18]$. TCS is related to various human health 
issues; furthermore, it has been defined as endocrine disruptor $[19,20]$. These characteristics have led to its partial prohibition in many countries, such as Canada [21], a complete ban in over-the-counter (OTC) consumer antiseptic wash products, such as liquid/foam/gel hand soaps or body washes in the Federal Rule 84 FR 14847 by the U.S. Food and Drug Administration (USFDA) [22] or disapproval for use in human hygiene biocidal products by the EU [23].

Thus, developing cost-effective remediation technologies that prevent the presence of this pollutant in natural resources constitutes a techno-scientific challenge. Advanced oxidation processes (AOPs) came out as a set of alternative technologies to provide effective solutions to the degradation of persistent and emerging pollutants [2,24-28]. With regard to TCS degradation, photolytic treatments, photolysis and photocatalysis, have attracted the interest of the scientific community. Photocatalysis takes place when a semiconductor, the photocatalyst, absorbs photons that possess equal or higher energy than the photocatalyst band gap, generating electron-hole pairs $\left(\mathrm{e}^{-}\right.$and $\mathrm{h}^{+}$, respectively) on the catalyst surface [29]. These react with $\mathrm{H}_{2} \mathrm{O}$ producing reactive oxygen species, $\mathrm{ROS}$, responsible of the cleavage and consecutive changes of the molecule of interest [24,30,31].

When AOPs are applied to aqueous media containing organic compounds, the oxidation pathway goes through the formation of a number of intermediate compounds, which often tend to be more stable, and thus, more resistant to degradation. Moreover, these intermediates are sometimes more toxic than the parent compounds. Regarding the photocatalytic oxidation of TCS, the group of chlorophenols (CPs) containing highly toxic, bio-cumulative and scarcely biodegradable compounds appears to be present in most of the reported reaction pathways. Together with 2,4-dichlorophenol and other phenols, 2,8-dichlorodibenzo-p-dioxin, 4-chlorocatechol and diverse TCS derivatives have been detected during TCS photodegradation [32]. 2-Chlorophenol, 2,4-dichlorophenol, 2,4-6-trichlorophenol and pentachlorophenol were indexed in the priority pollutant list by the European Commission [33] and the USEPA's Clean Water Act [34].

In order to move photocatalysis to a harmless and green remediation technology for emerging pollutants such as TCS, a thorough understanding of the reaction pathway leading to the end products, as well as the kinetics of the entire process, becomes necessary. Most works to date have deepened the kinetics of the degradation of the parent compound and only a few provide kinetic constants; but a kinetic study of the formation of intermediate derivatives is still lacking [35-37]. Thus, the aim of this work is to contribute to increasing the knowledge of the application of remediation technologies that prevent the contamination of natural waters with emerging pollutants. More specifically, the kinetic model and parameters of the photocatalytic remediation of TCS-polluted waters are reported as a case study that provides methodological insight, which is useful to predict the performance of remediation technologies.

\section{Results and Discussion}

\subsection{Degradation Kinetics of the Parent (TCS) Compound}

An experimental plan was carried out to analyze the influence of the main process variables, i.e., catalyst loading and light power, on the rate of the disappearance of TCS and the formation of intermediate derivatives. First, the adsorption of TCS on the $\mathrm{TiO}_{2}$ surface was studied in experiments carried out at $\mathrm{pH} 5.8$ for $4 \mathrm{~h}$ in the dark, observing negligible adsorption. In these conditions, TCS is in a neutral form ( $\mathrm{pH}<\mathrm{pKa}$ ), so it is neutral-positively charged (TCS $\mathrm{pKa}=7.9-8.1$ ). $\mathrm{TiO}_{2}$ is positively charged because the $\mathrm{p}_{\mathrm{Zc}}$ value is below the solution $\mathrm{pH}\left(\mathrm{p}_{\mathrm{Zc}}=6.25\right)$; therefore, the adsorption and desorption properties of $\mathrm{TiO}_{2}$ may be affected by this attribute [36,38]. Then, due to the repulsion forces between TCS and $\mathrm{TiO}_{2}$, the adsorption is negligible.

Figure 1a shows time courses of TCS concentration under different $\mathrm{TiO}_{2}$ doses, using UV-A LEDs. First, an experiment without catalyst was carried out, and as can be observed, almost no degradation of triclosan was produced. Moreover, no influence in TCS degradation was found within the studied range of $\mathrm{TiO}_{2}$ concentrations. Experimental data are represented together with error bars, which were 
obtained after replication of the experiments. Figure $1 \mathrm{~b}$ shows the change in TCS concentration for different values of light power, again with a very small influence of this variable. By working at the maximum power at which TCS is not degraded by photolysis $(35 \mathrm{~W})$, we guarantee working with the maximum photon flux.
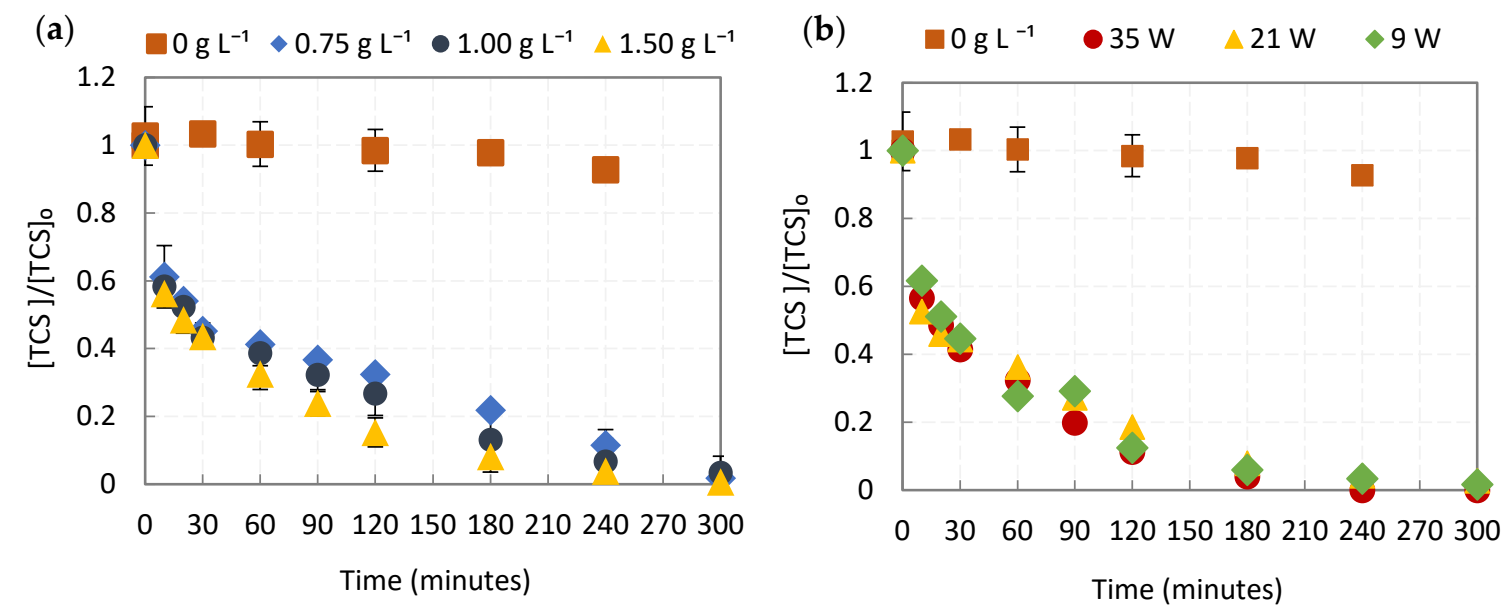

Figure 1. Influence of (a) $\mathrm{TiO}_{2}$ loading working at $35 \mathrm{~W}$ and (b) light power working with $1.5 \mathrm{~g} \mathrm{~L}^{-1}$ of $\mathrm{TiO}_{2}$.

\subsubsection{TCS Intermediate Derivatives}

The intermediate derivatives identified in this work have been classified in two main groups, higher concentration compounds, HICs, and lower concentration compounds, LOCs, according to the measured area. HICs were formed from a small modification of the TCS molecule, whereas LOCs were produced by the cleavage of the TCS molecule. Table 1 shows the identified compounds with their retention time and characteristic ions. The corresponding mass spectra of HICs are shown in Figure S1, Supplementary Materials.

Within HICs, a set of four compounds were identified and corroborated with the bibliography, which were named TCS derivatives (Table 1, Nos. 1-4). The first one is the TCS quinone (No. 1), with mass spectra and characteristic ions in good agreement with the works of Yu et al. and Zhang and Huang $[39,40]$. The other three compounds belong to the group named hydroxylated TCS, whose main difference lies in the position where the ${ }^{\bullet} \mathrm{OH}$ radical was added to a carbon atom of the TCS molecule [37]. It is hard to know the position in the ring where the ${ }^{\bullet} \mathrm{OH}$ was added, so generic representations of these molecules are depicted in Table 1 (Nos. 2-4). Sankoda et al. [41] established that there are six feasible positions where ${ }^{\bullet} \mathrm{OH}$ radicals can be added to the molecule to generate six hydroxylated derivatives. ${ }^{\bullet} \mathrm{OH}$ radicals possess a strong electrophilic character and have a tendency to attack the carbon atoms with the highest electron density, so ${ }^{\bullet} \mathrm{OH}$ radical preferentially attacks the chlorophenolic ring, producing hydroxylated TCS $1[37,40,41]$. Hydroxylated TCS 2 and 3 were produced when ${ }^{\bullet} \mathrm{OH}$ was added to the non-phenolic ring [37]. The similarity between the mass spectra of hydroxylated TCS 2 and 3 is noticeable. However, the small existing differences, such as the mass fragments with high molecular weight and the relative abundance of the molecular ion and fragment ions, suggest that they are different molecules. TCS quinone and the different hydroxylated TCS were not authenticated due to the commercial unavailability of standard compounds. Finally, LOCs such as chloro-aromatic derivatives 2-chloro-p-benzoquinone, 2,4-dichlorophenol, 2-chlorohydroquinone, 3,5-dichlorobenzene-1,2-diol and 4-chlorocatechol were identified by GC-MS using the NIST08 library. 
Table 1. Summary of the identified higher concentration compounds (HICs) and lower concentration compounds (LOCs).

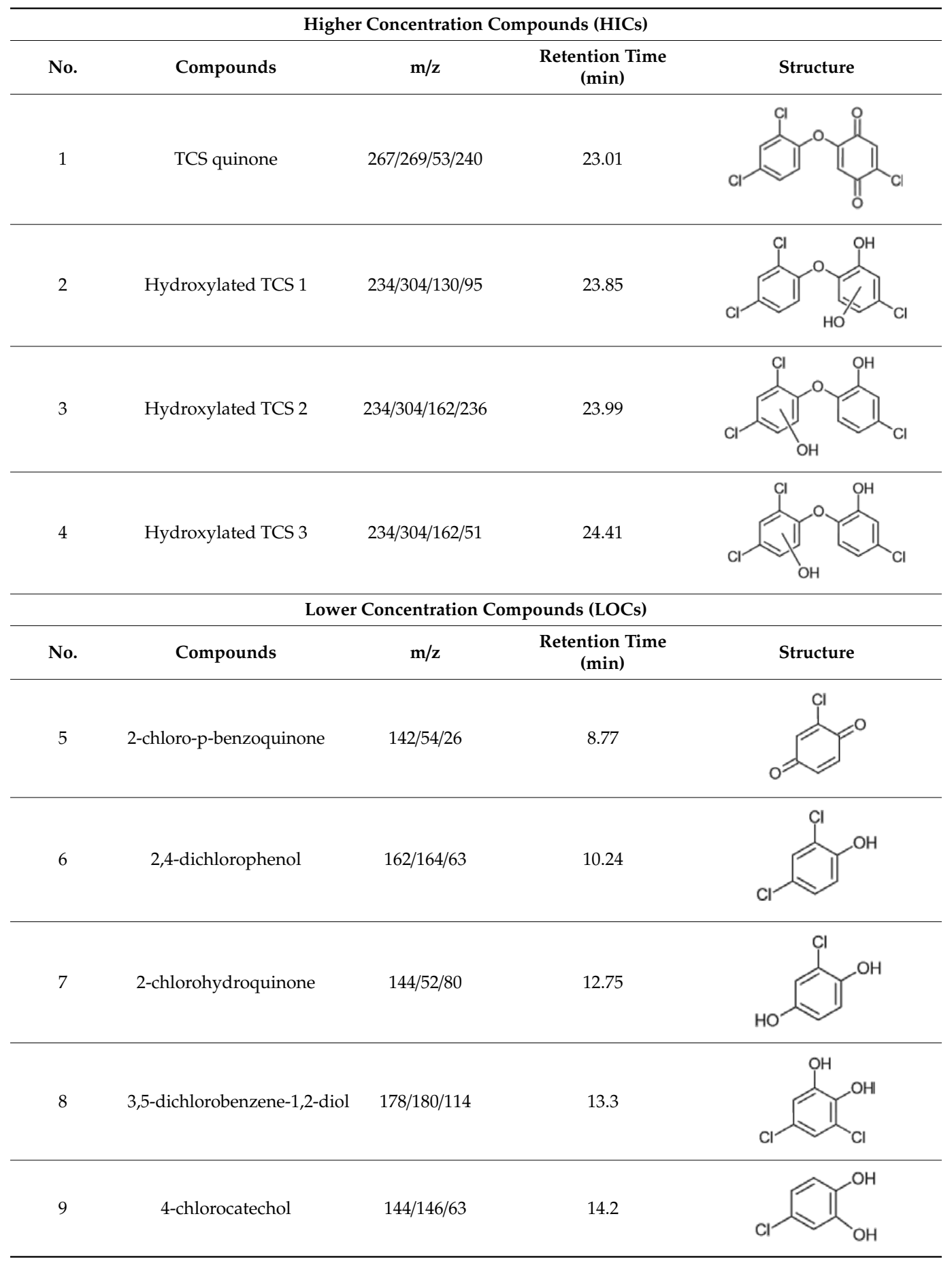

\subsubsection{TCS Degradation Pathways}

In order to understand the degradation pathway of the photocatalytic transformation of triclosan, a mechanism was proposed based on our experimental results and previous literature reports (Figure 2) [32,35-37,39,41,42]. The first step in TCS decomposition could generate TCS derivatives through chlorination and dechlorination mechanisms (route 1, chlorinated TCS and/or dechlorinated TCS) or the rearrangement of the molecule (route 2, TCS hydroquinone and route 3, TCS quinone, hydroxylated TCS 1, hydroxylated TCS 2 and hydroxylated TCS 3). These were formed due to the 
-OH-TCS adduct, produced immediately after the attack of ${ }^{\bullet} \mathrm{OH}$ radicals, and as a consequence of its instability, it ends up in a semi-quinone radical, which leads to the formation of different TCS derivatives $[35,39,42]$. Generally, this is followed by the cleavage of the molecule, producing different phenolic compounds, such as 2,4-dichlorophenol, among others (routes 4 and 5). 2,4-Dichlorophenol gives rise to 2-chlorohydroquinone, through the loss of a chlorine atom and ${ }^{\bullet} \mathrm{OH}$ addition (route 6), and then it transforms into 2-chloro-p-benzoquinone (route 7). Moreover, 2,4-dichlorophenol generates 3,5-dichlorobenzene-1,2-diol through ${ }^{\bullet} \mathrm{OH}$ addition (route 8) and 4-chlorocatechol, also through the loss of a chlorine atom and ${ }^{\bullet} \mathrm{OH}$ addition (route 9). Finally, these molecules are broken, giving smaller products such as carboxylic acids. Chlorinated TCS and dechlorinated TCS, depicted in Figure 2, are represented as generic molecules. Chlorinated TCS with four or five chlorine atoms can be named as tetraclosan or pentaclosan. In the same way, dechlorinated TCS can appear in different forms, depending where the atoms are placed [41,42]. Compounds detected in this work have been marked in yellow in Figure 2.

\subsection{Kinetic Analysis and Modeling}

In order to follow the change in the concentration of the parent TCS and the photocatalytically obtained derivatives, different samples were withdrawn at selected time values $(10 ; 30 ; 60 ; 90 ; 130$; 180; and $300 \mathrm{~min}$ ) and the procedure described in the experimental section was followed. Figure 3 depicts the time courses of TCS and 2,4-dichlorophenol concentration, with the corresponding error bars, representing the standard deviations of four replicates. 2,4-Dichlorophenol showed the highest concentration of all identified derivatives; it was produced gradually, reaching a maximum value of approx. $0.0049 \mathrm{mM}$ and then the concentration started decreasing smoothly.

Figure 4a shows the time courses of HIC derivatives (detailed in Table 1) in terms of peak area. TCS quinone and hydroxylated TCS 1 presented much higher peak areas than hydroxylated TCS 2 and TCS 3; besides, TCS quinone was formed faster than hydroxylated TCS; all of them reached a maximum and then decreased. Negligible signal was obtained for all the compounds after ca. $180 \mathrm{~min}$.

Figure $4 \mathrm{~b}$ depicts peak areas of LOC derivatives; 2,4-dichlorophenol presented the highest peak area of all and, in contrast, the lowest area value of LOCs belongs to 2-chloro-p-benzoquinone. The trend was similar to that observed for HIC derivatives; LOCs were formed, reached a maximum around $30 \mathrm{~min}$ and then started decreasing until almost complete disappearance.

After identifying TCS derivatives and in order to proceed with the kinetic modeling, a carbon balance was carried out, by multiplying the peak area of each compound by its corresponding number of carbon atoms. This facilitated the expression of the concentration of the different derivatives in terms of the number of carbon moles. Additionally, for the best treatment of the data, the concentrations of HICs (hydroxylated TCS 1, 2 and 3) were added, obtaining a lumped value, $\Sigma H I C s ;$ the same procedure was followed with LOC derivatives (2-chloro-p-benzoquinone, 2-chlorohydroquinone, 3,5-dichlorobenzene-1,2-diol and 4-chlorocatechol), to obtain $\Sigma$ LOCs, excluding 2,4-dichlorophenol due to its higher concentration. TCS degradation occurs while the other compounds appear, with HICs being the first group of derivatives formed during the photocatalytic oxidation of TCS, reaching the maximum value in the interval of 10-30 $\mathrm{min}$, then 2,4-dichlorophenol was formed. This compound increases until a maximum around $30 \mathrm{~min}$ and then decreases. Finally, LOCs have a similar tendency, although with lower peak areas, as can be seen in Figure 5. To the extent of the authors' knowledge, there has been no previous research about the kinetic model considering the formed intermediate derivatives. 


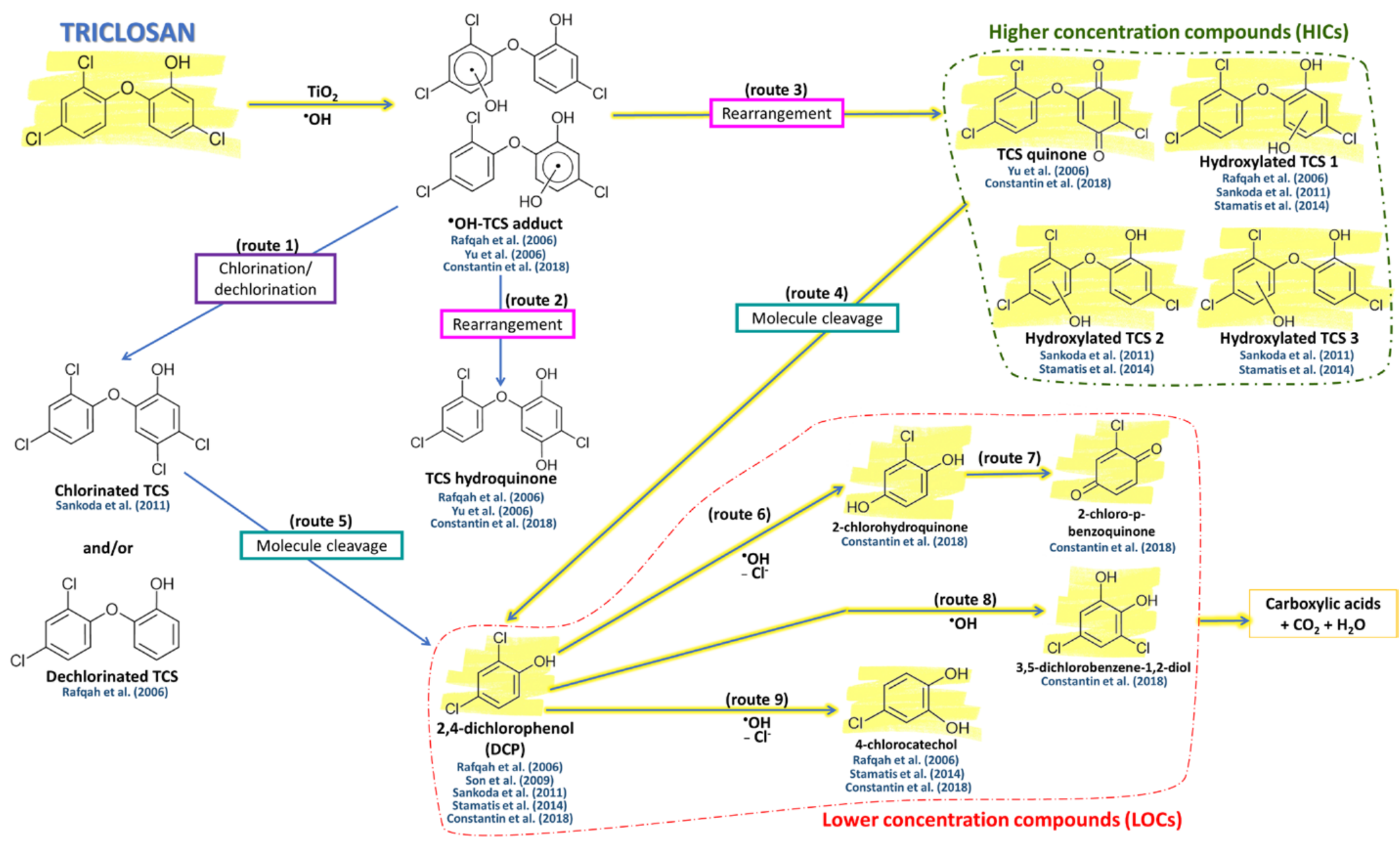

Figure 2. Summary of the main photodegradation mechanisms of Triclosan (TCS). $\square$ Detected in this work. Adapted from the literature [32,35-37,39,41,42]. 


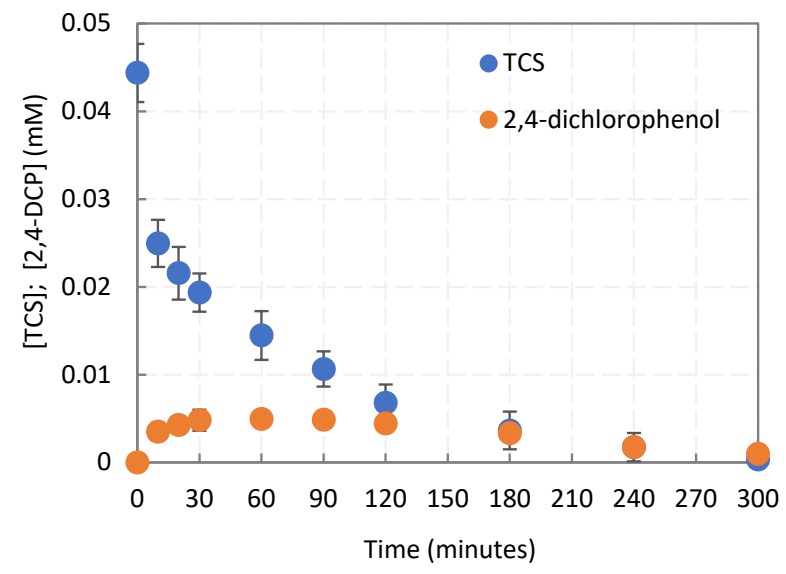

Figure 3. Time course of TCS and 2,4-dichlorophenol (conditions: $[\mathrm{TCS}]_{0}=10 \mathrm{mg} \mathrm{L}{ }^{-1}$, $\left.\left(\mathrm{TiO}_{2}\right)=1.50 \mathrm{~g} \mathrm{~L}^{-1}, \mathrm{pH}_{0}=5.8\right)$.
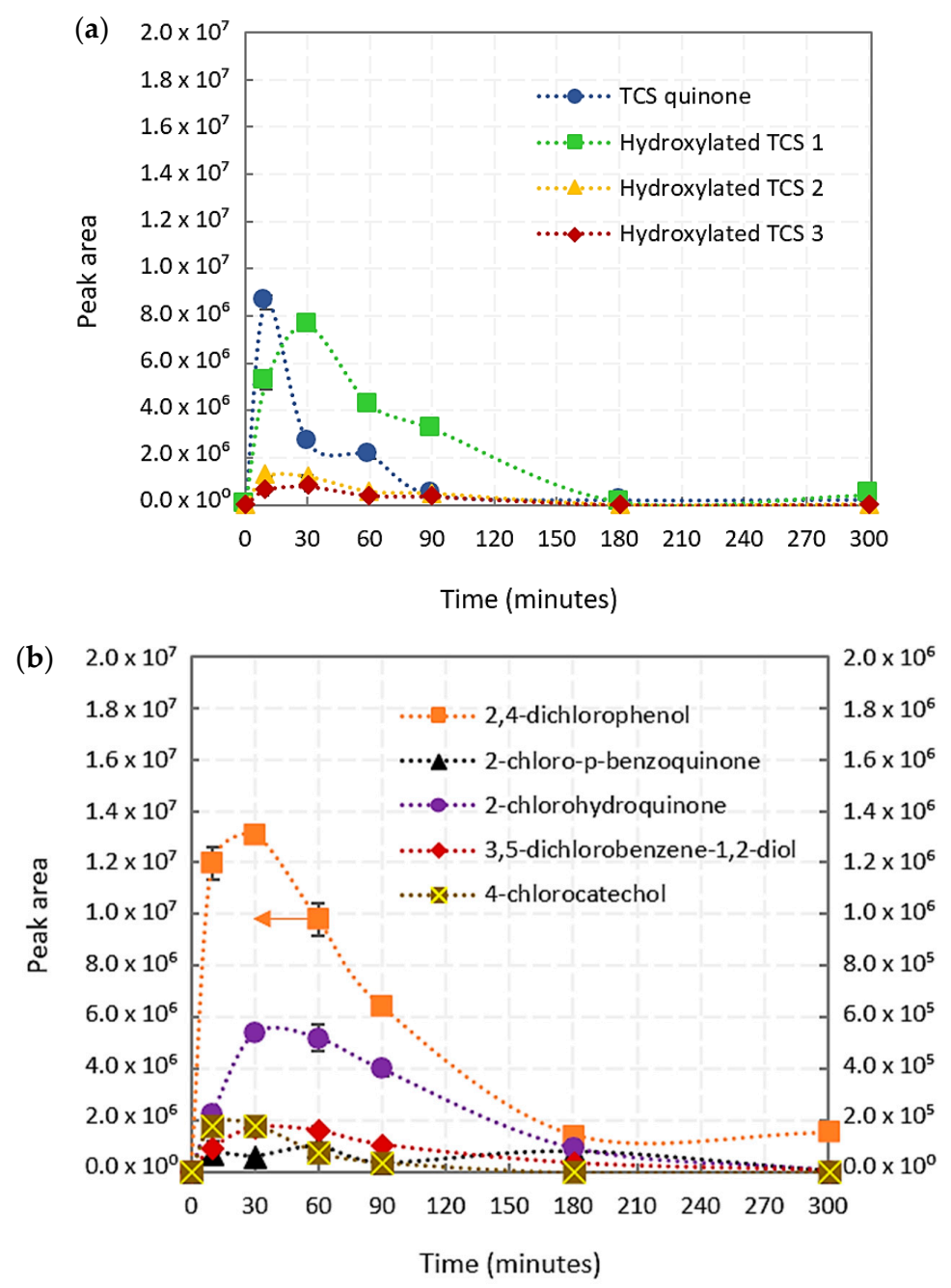

Figure 4. Time courses of (a) HICs and (b) LOCs derivatives formed during TCS photocatalysis. Lines have been added for a better readability of the data. 


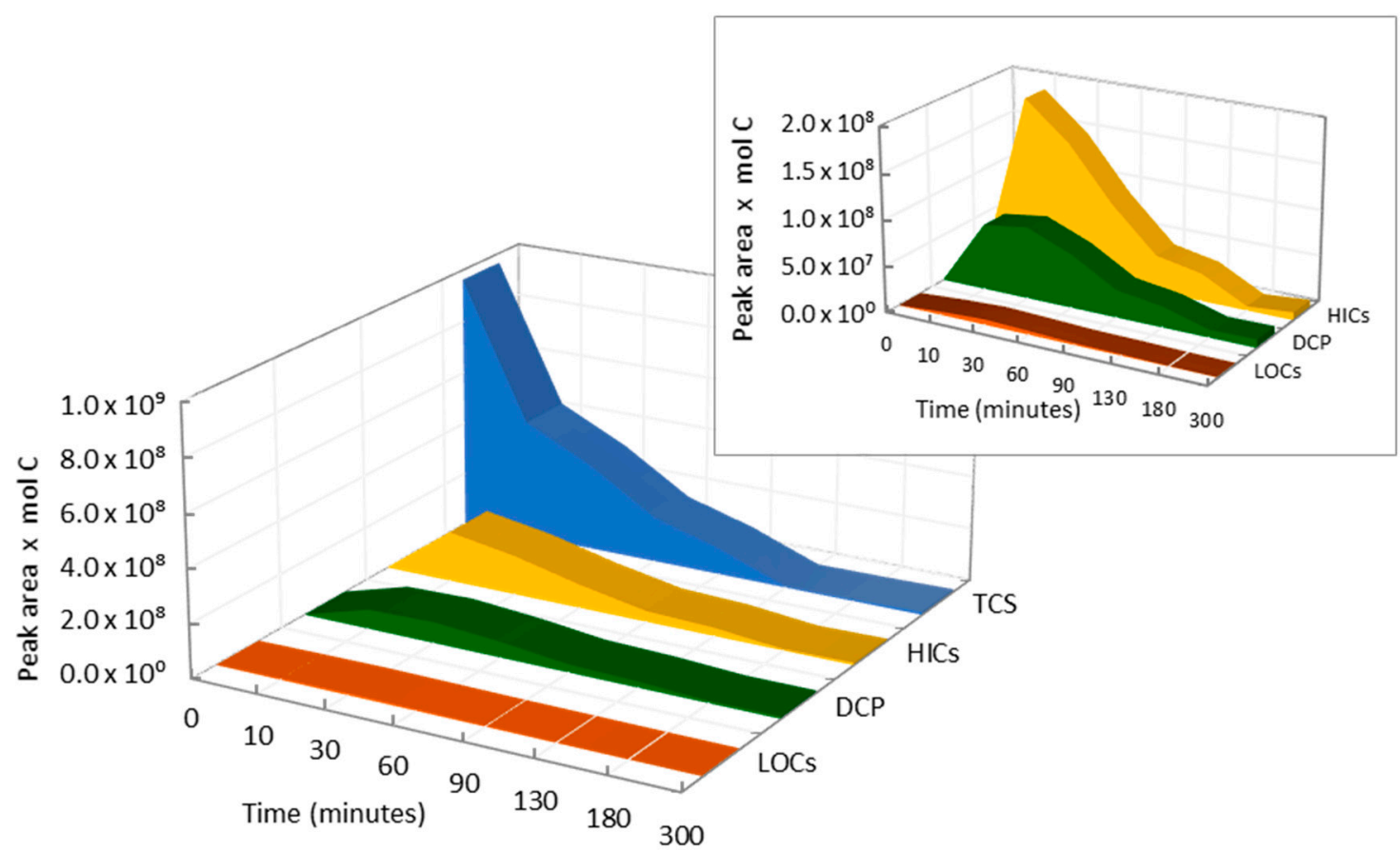

Figure 5. Disappearance of the parent TCS and formation of intermediate derivatives throughout the photocatalytic experiments.

As has been stated in Section 2.1.2, some authors proposed that the TCS molecule suffers hydroxylation, while different authors propose that TCS breaks due to the ${ }^{\bullet} \mathrm{OH}$ action $[35-37,39,41,42]$. Based on the behavior of the intermediate derivatives and supported by the reviewed literature related to TCS photocatalysis, a reaction scheme is proposed in Equation (1). It is well known that oxidation reactions tend to follow a mechanism with consecutive reactions. Equation (1) represents the stoichiometric equations following TCS photocatalytic degradation. Triclosan (TCS) decomposes, leading to higher concentration compounds (HICs); the latter decompose to 2,4-dichlorophenol (DCP) and 2,4-dichlorophenol decomposes, forming lower concentration by-products (LOCs). Finally, LOCs are oxidized to carboxylic acids, $\mathrm{CO}_{2}$ and $\mathrm{H}_{2} \mathrm{O}(\mathrm{P})$.

$$
\mathrm{TCS} \stackrel{\mathrm{k}_{1}}{\rightarrow} \Sigma \mathrm{HICs} \stackrel{\mathrm{k}_{2}}{\rightarrow} \mathrm{DCP} \stackrel{\mathrm{k}_{3}}{\rightarrow} \Sigma \mathrm{LOCs} \stackrel{\mathrm{k}_{4}}{\rightarrow} \text { Carboxylic acids }+\mathrm{CO}_{2}+\mathrm{H}_{2} \mathrm{O}
$$

For the kinetic modeling, the rate of all degradation and formation reactions has been described by a series of first order kinetic equations, where $\mathrm{k}_{1}, \mathrm{k}_{2}, \mathrm{k}_{3}$ and $\mathrm{k}_{4}$ are the kinetic constants $\left(\mathrm{min}^{-1}\right)$; the kinetic model is expressed by Equations (2)-(6). $k_{1}$ thereby corresponds to the reaction of TCS degradation and HIC formation, $\mathrm{k}_{2}$ to the disappearance of HICs and the formation of DCP, $\mathrm{k}_{3}$ to DCP degradation and LOC formation and finally, $\mathrm{k}_{4}$ to LOC disappearance and the formation of the carboxylic acids, $\mathrm{CO}_{2}$ and $\mathrm{H}_{2} \mathrm{O}$.

$$
\begin{gathered}
\frac{\mathrm{dTCS}}{\mathrm{dt}}=-\mathrm{k}_{1}[\mathrm{TCS}] \\
\frac{\mathrm{dHICs}}{\mathrm{dt}}=\mathrm{k}_{1}[\mathrm{TCS}]-\mathrm{k}_{2}[\mathrm{HICs}] \\
\frac{\mathrm{dDCP}}{\mathrm{dt}}=\mathrm{k}_{2}[\mathrm{HICs}]-\mathrm{k}_{3}[\mathrm{DCP}] \\
\frac{\mathrm{dLOCs}}{\mathrm{dt}}=\mathrm{k}_{3}[\mathrm{DCP}]-\mathrm{k}_{4}[\text { LOCs }] \\
\frac{\mathrm{dP}}{\mathrm{dt}}=\mathrm{k}_{4}[\text { LOCs }]
\end{gathered}
$$


Aspen Custom Modeler software was employed to numerically solve the system of Equations (2)-(6). Figure 6 pictures the best fit between the model and the experimental data. The values of the kinetic constants were $4.20 \cdot 10^{-2}, 1.00 \cdot 10^{-1}, 1.95 \cdot 10^{-1}$ and $2.92 \cdot 10^{0} \min ^{-1}$ for $\mathrm{k}_{1}, \mathrm{k}_{2}, \mathrm{k}_{3}$ and $\mathrm{k}_{4}$, respectively.
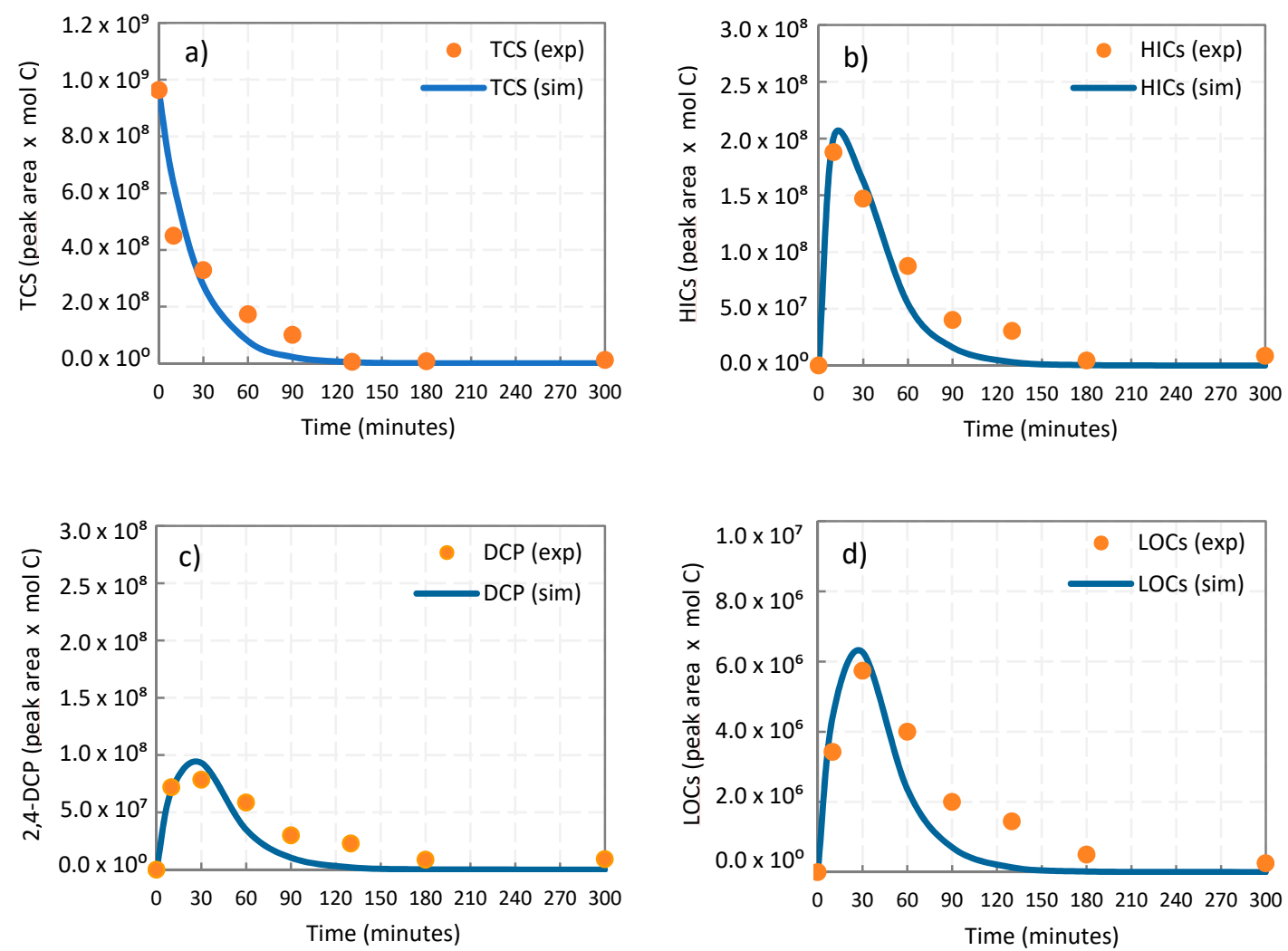

Figure 6. Fitting of simulated and experimental data of (a) TCS photocatalysis, (b) higher concentration derivatives (HICs), (c) 2,4-dichlorophenol (DCP) and (d) lower concentration derivatives (LOCs).

Table 2 summarizes the kinetic model and parameters and collects the values previously reported in the literature. The highest value of the $\mathrm{k}_{1}$ kinetic constant, $2.16 \cdot 10^{-1} \mathrm{~min}^{-1}$, was reported by Son et al. (2009) [36], working with $0.1 \mathrm{~g} \mathrm{~L}^{-1}$ of $\mathrm{TiO}_{2}$ and treating $0.87 \mathrm{mg} \mathrm{L}^{-1}$ of TCS. Constantin et al. (2018) [35] reported the lowest $\mathrm{k}$ value, $2.50 \cdot 10^{-2} \mathrm{~min}^{-1}$, treating $31 \mathrm{mg} \mathrm{L}^{-1}$ of TCS, and this can be attributed to the highest concentration of TCS, that reaches the highest value of all reported works, along with the amount of $\mathrm{TiO}_{2}$ employed. In the present work, the $\mathrm{k}_{1}$ value for TCS degradation is lower, but still in the range of the rest of the kinetic constants collected in Table 2. As can be seen, as the concentration of TCS decreases, the $\mathrm{k}$ value increases, keeping the rest of the variables constant; this means that the reported values correspond to apparent kinetic constants that depend on the concentration of the pollutants. Intrinsic kinetic constants would need an experimental plan with the individual compounds; therefore, this work constitutes a methodological path that helps in the design of remediation technologies. 
Table 2. TCS kinetic constants in photocatalytic experiments.

\begin{tabular}{|c|c|c|c|}
\hline \multicolumn{4}{|c|}{ Photocatalysis } \\
\hline \multirow{2}{*}{ Conditions } & \multicolumn{2}{|c|}{ Kinetic Equations and Parameters } & \multirow{2}{*}{ Ref. } \\
\hline & Kinetic Equations & $k\left(\min ^{-1}\right)$ & \\
\hline $\begin{array}{c}\mathrm{TCS}_{0}=30 \mu \mathrm{M}\left(8.7 \mathrm{mg} \mathrm{L}^{-1}\right) ; \mathrm{TiO}_{2}=0.1 \mathrm{~g} \mathrm{~L}^{-1} ; \mathrm{V}=0.15 \mathrm{~L} ; \\
\mathrm{pH}=\text { neutral; } \mathrm{Hg} \text { lamp }(\mathrm{UV}-\mathrm{A})=450 \mathrm{~W}, \lambda=365 \mathrm{~nm} ; \\
\text { Light intensity }=1.37 \cdot 10^{-4} \text { Einstein } \mathrm{L}^{-1} \mathrm{~min}^{-1}\end{array}$ & \multirow{5}{*}{$\begin{array}{l}-\frac{\mathrm{dTCS}}{\mathrm{dt}}=\mathrm{k}[\mathrm{TCS}] \\
(\mathrm{k} \text { values given at } 5 \mathrm{~min})\end{array}$} & $\mathrm{k}_{1}=1.67 \cdot 10^{-1}$ & \multirow{5}{*}[36]{} \\
\hline $\begin{array}{c}\mathrm{TCS}_{0}=17 \mu \mathrm{M}\left(4.92 \mathrm{mg} \mathrm{L}^{-1}\right) ; \mathrm{TiO}_{2}=0.1 \mathrm{~g} \mathrm{~L}^{-1} \\
\mathrm{~V}=0.15 \mathrm{~L} ; \mathrm{pH}=\text { neutral; } \mathrm{Hg} \text { lamp }(\mathrm{UV}-\mathrm{A})=450 \mathrm{~W} \\
\lambda=365 \mathrm{~nm} ; \text { Light intensity }=1.37 \cdot 10^{-4} \text { Einstein } \mathrm{L}^{-1} \mathrm{~min}^{-1}\end{array}$ & & $\mathrm{k}_{2}=1.71 \cdot 10^{-1}$ & \\
\hline $\begin{array}{c}\mathrm{TCS}_{0}=10 \mu \mathrm{M}\left(2.89 \mathrm{mg} \mathrm{L}^{-1}\right) ; \mathrm{TiO}_{2}=0.1 \mathrm{~g} \mathrm{~L}^{-1} \\
\mathrm{~V}=0.15 \mathrm{~L} ; \mathrm{pH}=\text { neutral; } \mathrm{Hg} \text { lamp (UV-A })=450 \mathrm{~W} \\
\lambda=365 \mathrm{~nm} ; \text { Light intensity }=1.37 \cdot 10^{-4} \text { Einstein } \mathrm{L}^{-1} \mathrm{~min}^{-1}\end{array}$ & & $\mathrm{k}_{3}=1.87 \cdot 10^{-1}$ & \\
\hline $\begin{array}{c}\mathrm{TCS}_{0}=7 \mu \mathrm{M}\left(2.02 \mathrm{mg} \mathrm{L}^{-1}\right) ; \mathrm{TiO}_{2}=0.1 \mathrm{~g} \mathrm{~L}^{-1} ; \mathrm{V}=0.15 \mathrm{~L} ; \\
\mathrm{pH}=\text { neutral; } \mathrm{Hg} \text { lamp }(\mathrm{UV}-\mathrm{A})=450 \mathrm{~W}, \lambda=365 \mathrm{~nm} ; \\
\text { Light intensity }=1.37 \cdot 10^{-4} \text { Einstein } \mathrm{L}^{-1} \mathrm{~min}^{-1}\end{array}$ & & $\mathrm{k}_{4}=2.02 \cdot 10^{-1}$ & \\
\hline $\begin{array}{c}\mathrm{TCS}_{0}=3 \mu \mathrm{M}\left(0.87 \mathrm{mg} \mathrm{L}^{-1}\right) ; \mathrm{TiO}_{2}=0.1 \mathrm{~g} \mathrm{~L}^{-1} ; \mathrm{V}=0.15 \mathrm{~L} \\
\mathrm{pH}=\text { neutral; Hg lamp }(\mathrm{UV}-\mathrm{A})=450 \mathrm{~W}, \lambda=365 \mathrm{~nm} ; \\
\text { Light intensity }=1.37 \cdot 10^{-4} \text { Einstein } \mathrm{L}^{-1} \mathrm{~min}^{-1}\end{array}$ & & $\mathrm{k}_{5}=2.16 \cdot 10^{-1}$ & \\
\hline $\begin{array}{c}\mathrm{TCS}_{0}=3.45 \mu \mathrm{M}\left(1 \mathrm{mg} \mathrm{L}{ }^{-1}\right) ; \mathrm{TiO}_{2}=0.5 \mathrm{~g} \mathrm{~L}^{-1} ; \mathrm{V}=0.25 \mathrm{~L} \\
\mathrm{pH}=6.6 ; \text { Xe lamp }(\mathrm{UV})=2.2 \mathrm{~kW}, \lambda=>290 \mathrm{~nm}\end{array}$ & $-\frac{\mathrm{dTCS}}{\mathrm{dt}}=\mathrm{k}_{1}[\mathrm{TCS}]$ & $\begin{array}{l}\mathrm{k}_{1}=1.50 \cdot 10^{-1} \\
\mathrm{t}_{1 / 2}=4.61 \mathrm{~min}\end{array}$ & [37] \\
\hline $\begin{array}{l}\mathrm{TCS}_{0}=109.8 \mu \mathrm{M}\left(31.8 \mathrm{mg} \mathrm{L}^{-1}\right) ; \mathrm{TiO}_{2}=0.2 \mathrm{~g} \mathrm{~L}^{-1} ; \mathrm{pH}=6.5 ; \\
\mathrm{UV}=300-400 \mathrm{~nm} ; \text { Light intensity }=1.05 \cdot 10^{-6} \text { Einstein s}{ }^{-1}\end{array}$ & $-\frac{\mathrm{dTCS}}{\mathrm{dt}}=\mathrm{k}_{1}[\mathrm{TCS}]$ & $\mathrm{k}_{1}=2.50 \cdot 10^{-2}$ & [35] \\
\hline $\begin{array}{c}\mathrm{TCS}_{0}=34.5 \mu \mathrm{M}\left(10 \mathrm{mg} \mathrm{L}^{-1}\right) ; \mathrm{TiO}_{2}=1.5 \mathrm{~g} \mathrm{~L}^{-1} ; \mathrm{V}=1 \mathrm{~L} ; \\
\mathrm{pH}=5.8 ; \mathrm{LED} \operatorname{lamp}(\mathrm{UV})=35 \mathrm{~W}, \lambda=365 \mathrm{~nm}\end{array}$ & $\begin{array}{c}\frac{\mathrm{dTCS}}{\mathrm{dt}}=-\mathrm{k}_{1}[\mathrm{TCS}] \\
\frac{\mathrm{dHICs}}{\mathrm{dt}}=\mathrm{k}_{1}[\mathrm{TCS}]-\mathrm{k}_{2}[\mathrm{HICs}] \\
\frac{\mathrm{dDCP}}{\mathrm{dt}}=\mathrm{k}_{2}[\mathrm{HICs}]-\mathrm{k}_{3}[\mathrm{DCP}] \\
\frac{\mathrm{dLOCs}}{\mathrm{dt}}=\mathrm{k}_{3}[\mathrm{DCP}]-\mathrm{k}_{4}[\mathrm{LOCs}] \\
\frac{\mathrm{dP}}{\mathrm{dt}}=\mathrm{k}_{4}[\mathrm{LOCs}]\end{array}$ & $\begin{aligned} \mathrm{k}_{1} & =4.20 \cdot 10^{-2} \\
\mathrm{k}_{2} & =1.00 \cdot 10^{-1} \\
\mathrm{k}_{3} & =1.95 \cdot 10^{-1} \\
\mathrm{k}_{4} & =2.92 \cdot 10^{0}\end{aligned}$ & $\begin{array}{l}\text { This } \\
\text { work }\end{array}$ \\
\hline
\end{tabular}

Moreover, a review about the photocatalytic degradation kinetics of 2,4-dichlorophenol has been undertaken. Most studies have been carried out with higher concentrations of 2,4-dichlorophenol and have pointed to the dependency of the apparent kinetic parameters on the pollutant concentration, $\mathrm{pH}$ and light intensity. The reported values of kinetic parameters vary between the zeroth-order parameter value $4.00 \cdot 10^{-4} \mathrm{M} \mathrm{h}^{-1}$ reported by $\mathrm{Ku}$ and Hsieh [43] and the most recent first order parameter $5.11 \cdot 10^{-1}$ $\mathrm{min}^{-1}$, reported by Abeisch et al. [44] in the treatment of $50 \mathrm{mg} \mathrm{L}^{-1}$ of 2,4-dichlorophenol with 0.5 $\mathrm{g} \mathrm{L}^{-1}$ of $\mathrm{TiO}_{2}$ and $1000 \mathrm{~mW} \mathrm{~cm}{ }^{-2}$. Additional information on the reviewed kinetic constants of 2,4-dichlorophenol degradation is collected in Table S1, Supplementary Materials.

Thus, this work provides the kinetic model and parameters that describe the concentration of most TCS derivatives formed during the photocatalytic treatment providing a very useful tool for process design and control.

\section{Materials and Methods}

\subsection{Materials and Chemicals}

Triclosan ( $\geq 99 \%$ ) was provided by Alfa Aesar (Thermo Fisher Scientific, Waltham, MA, USA), 2,4-dichlorophenol (99\%, Sigma-Aldrich, Saint Louis, MO, USA) was employed as standard for HPLC. The catalyst was $\mathrm{TiO}_{2}$ powder Degussa P25 (80:20 anatase/rutile) with a specific surface of $50 \mathrm{~m}^{2}$ $\mathrm{g}^{-1}$, provided by Evonik Industries AG (Essen, Germany). Formic acid (85\%, Panreac, Barcelona, Spain) and acetonitrile LiChrosolv ${ }^{\circledR}(\geq 99.9 \%$, Merck, Darmstadt, Germany) were employed in HPLC 
analysis. Dichloromethane UniSolv ${ }^{\circledR}(\geq 99 \%$, Merck, Darmstadt, Germany) was used for intermediate product analysis. Syringe filters of $1 \mu \mathrm{m}$ APFB (Merck Millipore, Burlington, MA, USA) were employed. Deionized ultrapure Milli-Q water (resistivity $=18.2 \mathrm{M} \Omega \cdot \mathrm{cm}$ ) purified with a Milli-Q device (Millipore) was employed in the preparation of all solutions. The $\mathrm{pH}$ meter employed was a GLP 22 (Crison). Zeta potential was measured with a Zetasizer Nano ZS (Malvern Instruments, Malvern, Worcestershire, UK) and a zeta potential folded capillary cell (Malvern), by Laser Doppler Electrophoresis.

\subsection{Photocatalytic Experiments}

Photocatalytic solutions with an initial concentration of $10 \mathrm{mg} \mathrm{L}^{-1}$ of TCS were treated in a medium/high-power laboratory-scale photochemical plant provided with LED technology (APRIA Systems S.L., Guarnizo, Cantabria, Spain). It consists of a $1 \mathrm{~L}$ mixing tank where the solution was placed and pumped into a $0.25 \mathrm{~L}$ jacketed annular Pyrex reaction vessel; all elements were connected with flexible Teflon tubing. UVA-LEDs were located inside the inner tube of the reactor, with an emission wavelength of $365 \mathrm{~nm}$. The electrical power of the plant ranges from 0 to $54 \mathrm{~W}$ in the UV-A spectra. Moreover, the system contains a magnetic stirring plate operated at $1000 \mathrm{rpm}$ to maintain the homogeneity of the suspension, and a refrigeration bath to keep the temperature constant at $25^{\circ} \mathrm{C}$. The experimental set-up is represented in Figure 7 .

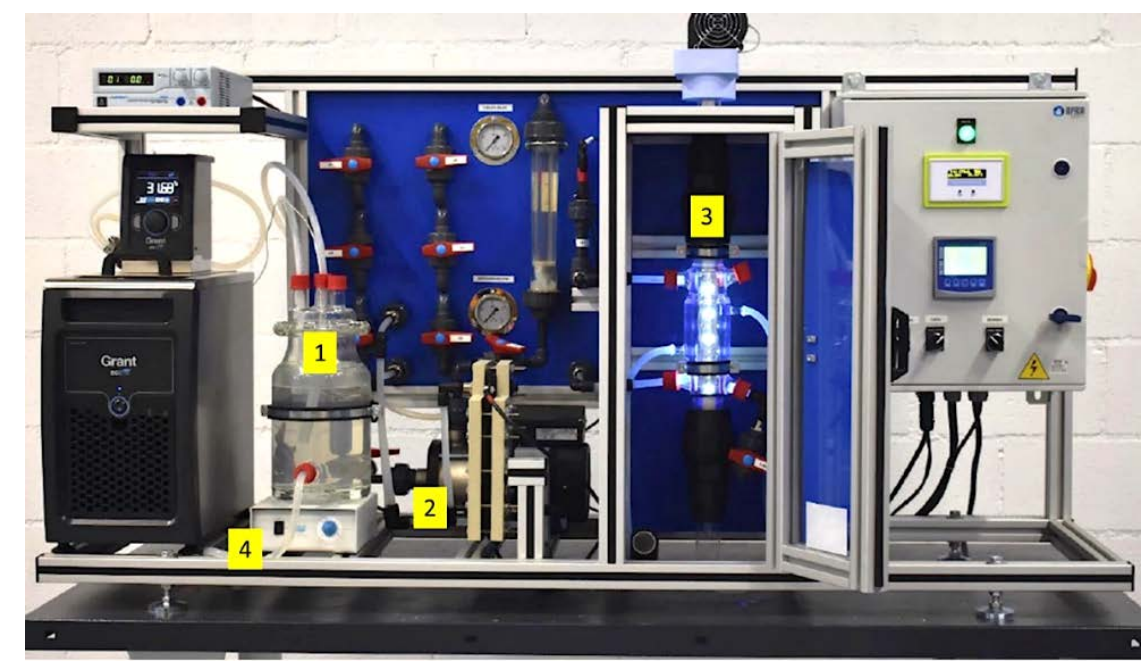

Figure 7. Experimental set-up, APRIA Systems; (1) mixing tank, (2) pump, (3) LED reactor and (4) magnetic stirrer.

Different catalyst doses of $\mathrm{TiO}_{2}$ were used $\left(0.75,1.0\right.$ and $\left.1.5 \mathrm{~g} \mathrm{~L}^{-1}\right)$ to perform the study. The electrical power applied in the experiments varied between 9-35 $\mathrm{W}$, and the working $\mathrm{pH}$ was 5.8 (the initial $\mathrm{pH}$ of the sample was not modified) until its complete degradation, reached after $5 \mathrm{~h}$. Before each photocatalytic experiment, the suspension with $\mathrm{TiO}_{2}$ flowed through the system in complete darkness for $2 \mathrm{~min}$ to reach the solute adsorption-desorption equilibrium. Then, the light was turned on to start the experiments. Different samples were taken at specified times and filtered through an APFB filter before storage in amber vials, until analysis. Two replicates of each experiment were carried out.

\subsection{Chemical Analysis}

The concentrations of triclosan and 2,4-dichlorophenol were analyzed in a high-performance liquid chromatograph (HPLC) Agilent Series 1100, employing an Agilent ZORBAX 80 ̊ Extend-C18 $5 \mu \mathrm{m}$ column $(3.0 \times 150 \mathrm{~mm})$ and photodiode array (PDA) detector (Agilent, Santa Clara, CA, USA). The analysis of TCS and 2,4-dichlorophenol followed the gradient elution method with acetonitrile and formic acid $(0.1 \% v / v)$ as a mobile phase at a flow rate of $1 \mathrm{~mL} \mathrm{~min}^{-1}$ : Eighty percent formic acid 
solution was eluted for $3 \mathrm{~min}$ with acetonitrile, $80 \%$ to $20 \%$ formic acid solution was eluted for the next $12 \mathrm{~min}$, followed by $20 \%$ to $0 \%$ formic acid for another $5 \mathrm{~min}$. Lastly, 100\% acetonitrile was eluted for $6 \mathrm{~min}$. The selected wavelength was $210 \mathrm{~nm}$ and the column was kept at $30^{\circ} \mathrm{C}$. The injection volume was $50 \mu \mathrm{L}$. Compounds were identified using authentic standards by matching their retention time and absorbance spectra. The retention times for 2,4-dichlorophenol and TCS were 9.7 and $14.2 \mathrm{~min}$, respectively.

Qualitative analysis for intermediate derivatives formed during the TCS photocatalytic experiments were performed by gas chromatography-mass spectrometry (GC-MS). The GC-MS was performed on Shimadzu QP2010 Ultra (Shimadzu, Kyoto, Japan) apparatus equipped with an auto-sampler. Separation occurred in an HP-5MS column $(30 \mathrm{~m} \times 0.25 \mathrm{~mm} \times 0.1 \mathrm{~mm})$ (Agilent, Santa Clara, CA, USA). Aliquots of samples $(500 \mathrm{~mL})$ were extracted twice with $50 \mathrm{~mL}$ of dichloromethane using a separatory funnel. The organic extract was concentrated up to $1 \mathrm{~mL}$, first, using a rotatory evaporator (R-210, BÜCHI Labortechnik AG, Flawil, Switzerland) and a gentle flow of $\mathrm{N}_{2}$ in a second step. The temperature program of the GC-MS oven was $60^{\circ} \mathrm{C}$, held for $3 \mathrm{~min}$, rate $10^{\circ} \mathrm{C} \mathrm{min}^{-1}$ to 320 ${ }^{\circ} \mathrm{C}$, held for $6 \mathrm{~min}$. Helium was employed as a carrier gas at a flow rate of $1 \mathrm{~mL} \mathrm{~min}^{-1}$. A volume sample of $2 \mu \mathrm{L}$ was injected in splitless mode and the injector temperature was set at $285^{\circ} \mathrm{C}$. The mass spectrometer (MS) was operated in electron impact ionization mode $(70 \mathrm{eV})$. Transfer line and ion source temperatures were 290 and $230{ }^{\circ} \mathrm{C}$, respectively. Data acquisition was in full scan mode with a range from $\mathrm{m} / \mathrm{z} 35$ to 400 . Identification of the intermediate derivatives produced during the oxidation treatment was carried out by comparison of their mass spectra with those from the NIST08 database. The change in the concentration of the intermediate derivatives was determined from the comparison of the areas of characteristic peaks at different oxidation times (10;30; 60; 90; 130; 180; and $300 \mathrm{~min}$ ).

\section{Conclusions}

This work advances the knowledge on photocatalytic wastewater remediation technologies for the degradation of persistent and emerging pollutants; besides the degradation of the parent compound, the kinetics of the formation of intermediate derivatives is also analyzed. The work progress has been applied to the photocatalytic degradation of TCS as a case study. TCS is an antimicrobial and antifungal compound that is found in natural waters as a result of its widespread use in consumer goods. The environmental and energy benefits offered by photocatalysis are promising in further deployment of the technology for the remediation of wastewaters containing emerging pollutants, but a deep understanding of the degradation pathways and kinetics is needed first. An experimental plan working with different catalyst doses $\left(0.75,1.00\right.$ and $1.50 \mathrm{~g} \mathrm{~L}^{-1}$ of $\left.\mathrm{TiO}_{2}\right)$ and light power $(9,21$ and $35 \mathrm{~W})$ was carried out in a medium/high-power laboratory-scale photochemical plant provided with LED technology. The main derivatives formed during TCS photocatalysis were identified from samples taken at different times. They were classified into two groups, higher concentration compounds (TCS quinone and three hydroxylated TCS compounds) and lower concentration compounds (2-chloro-p-benzoquinone, 2,4-dichlorophenol, 2-chlorohydroquinone, 3,5-dichlorobenzene-1,2-diol and 4-chlorocatechol).

Finally, after the proposal of the reaction pathway supported by the identified derivatives, the kinetic model was developed, starting with the formation of TCS derivatives at a higher concentration, which were degraded to the lower concentration compounds by the cleavage of the TCS molecule, and ended up as carboxylic acids, $\mathrm{CO}_{2}$ and water. The kinetic parameters obtained for the change of TCS and 2,4-dichlorophenol are in good agreement with previously reported values obtained from experiments performed under similar conditions. In addition, the kinetic model here reported can be used to predict the performance of water remediation technology.

Supplementary Materials: The following are available online at http://www.mdpi.com/2073-4344/10/12/1468/s1, Figure S1: GC-MS spectra of the TCS derivatives: (a) TCS quinone, (b) hydroxylated TCS 1, (c) hydroxylated TCS 2 and (d) hydroxylated TCS 3, Table S1: 2,4-dichlorophenol kinetic constants reviewed in bibliography. 
Author Contributions: Conceptualization, S.S., M ${ }^{a}$.-F.S.-R. and I.O.; Formal analysis, S.S., M ${ }^{\text {a }}$.-F.S.-R. and I.O.; Funding acquisition, M ${ }^{\mathrm{a}}$.-F.S.-R.; Investigation, S.S., M ${ }^{\mathrm{a}}$.-F.S.-R. and I.O.; Methodology, S.S., M ${ }^{\mathrm{a}}$.-F.S.-R. and I.O.; Project administration, $M^{\text {a }}$.-F.S.-R.; Supervision, $\mathrm{M}^{\mathrm{a}}$.-F.S.-R.; Writing—original draft, S.S.; Writing—review and editing, S.S., $\mathrm{M}^{\mathrm{a}}$.-F.S.-R. and I.O. All authors have read and agreed to the published version of the manuscript.

Funding: This research was funded by the Spanish Ministry of Economy and Competitiveness (MINECO) (CTM2017-87740-R and RTI2018-093310-B-I00).

Acknowledgments: S.S. is grateful for the FPI contract grant, PRE2018-083526.

Conflicts of Interest: The authors declare no conflict of interest.

\section{References}

1. Ortiz Uribe, I.; Mosquera-Corral, A.; Lema Rodicio, J.; Esplugas, S. Advanced technologies for water treatment and reuse. Am. Inst. Chem. Eng. 2015, 61, 3146-3158. [CrossRef]

2. Solá-Gutiérrez, C.; San Román, M.F.; Ortiz, I. Fate and hazard of the electrochemical oxidation of triclosan. Evaluation of polychlorodibenzo-p-dioxins and polychlorodibenzofurans (PCDD/Fs) formation. Sci. Total Environ. 2018, 626, 126-133. [CrossRef] [PubMed]

3. Dhillon, G.S.; Kaur, S.; Pulicharla, R.; Brar, S.K.; Cledón, M.; Verma, M.; Surampalli, R.Y. Triclosan: Current status, occurrence, environmental risks and bioaccumulation potential. Int. J. Environ. Res. Public Health 2015, 12, 5657-5684. [CrossRef] [PubMed]

4. Ruszkiewicz, J.A.; Li, S.; Rodriguez, M.B.; Aschner, M. Is Triclosan a neurotoxic agent? J. Toxicol. Environ. Heal. Part B Crit. Rev. 2017, 20, 104-117. [CrossRef] [PubMed]

5. Dann, A.B.; Hontela, A. Triclosan: Environmental exposure, toxicity and mechanisms of action. J. Appl. Toxicol. 2011, 31, 285-311. [CrossRef]

6. Bester, K. Triclosan in a sewage treatment process-Balances and monitoring data. Water Res. 2003, 37, 3891-3896. [CrossRef]

7. Canosa, P.; Rodríguez, I.; Rubí, E.; Cela, R. Determination of parabens and triclosan in indoor dust using matrix solid-phase dispersion and gas chromatography with tandem mass spectrometry. Anal. Chem. 2007, 79, 1675-1681. [CrossRef]

8. Chen, J.; Hartmann, E.M.; Kline, J.; Van Den Wymelenberg, K.; Halden, R.U. Assessment of human exposure to triclocarban, triclosan and five parabens in U.S. indoor dust using dispersive solid phase extraction followed by liquid chromatography tandem mass spectrometry. J. Hazard. Mater. 2018, 360, 623-630. [CrossRef]

9. Pedrouzo, M.; Borrull, F.; Marcé, R.M.; Pocurull, E. Stir-bar-sorptive extraction and ultra-high-performance liquid chromatography-tandem mass spectrometry for simultaneous analysis of UV filters and antimicrobial agents in water samples. Anal. Bioanal. Chem. 2010, 397, 2833-2839. [CrossRef]

10. Kookana, R.S.; Ying, G.G.; Waller, N.J. Triclosan: Its occurrence, fate and effects in the Australian environment. Water Sci. Technol. 2011, 63, 598-604. [CrossRef]

11. Villaverde-De-Sáa, E.; González-Mariño, I.; Quintana, J.B.; Rodil, R.; Rodríguez, I.; Cela, R. In-sample acetylation-non-porous membrane-assisted liquid-liquid extraction for the determination of parabens and triclosan in water samples. Anal. Bioanal. Chem. 2010, 397, 2559-2568. [CrossRef] [PubMed]

12. Archer, E.; Petrie, B.; Kasprzyk-Hordern, B.; Wolfaardt, G.M. The fate of pharmaceuticals and personal care products (PPCPs), endocrine disrupting contaminants (EDCs), metabolites and illicit drugs in a WWTW and environmental waters. Chemosphere 2017, 174, 437-446. [CrossRef] [PubMed]

13. Mohan, S.; Balakrishnan, P. Triclosan in treated wastewater from a city wastewater treatment plant and its environmental risk assessment. Water. Air. Soil Pollut. 2019, 230, 69. [CrossRef]

14. Ricart, M.; Guasch, H.; Alberch, M.; Barceló, D.; Bonnineau, C.; Geiszingerb, A.; Ferrer, J.; Ricciardi, F.; Romaní, A.M.; Morin, S.; et al. Triclosan persistence through wastewater treatment plants and its potential: Toxic effects on river biofilms. Aquat. Toxicol. 2010, 100, 346-353. [CrossRef]

15. Bedoux, G.; Roig, B.; Thomas, O.; Dupont, V.; Le Bot, B. Occurrence and toxicity of antimicrobial triclosan and by-products in the environment. Environ. Sci. Pollut. Res. 2012, 19, 1044-1065. [CrossRef]

16. Guruge, K.S.; Goswami, P.; Tanoue, R.; Nomiyama, K.; Wijesekara, R.G.S.; Dharmaratne, T.S. First nationwide investigation and environmental risk assessment of 72 pharmaceuticals and personal care products from Sri Lankan surface waterways. Sci. Total Environ. 2019, 690, 683-695. [CrossRef] 
17. Hewitt, N.J.; Grégoire, S.; Cubberley, R.; Duplan, H.; Eilstein, J.; Ellison, C.; Lester, C.; Fabian, E.; Fernandez, J.; Géniès, C.; et al. Measurement of the penetration of 56 cosmetic relevant chemicals into and through human skin using a standardized protocol. J. Appl. Toxicol. 2019, 40, 403-415. [CrossRef]

18. Wang, L.; Asimakopoulos, A.G.; Kannan, K. Accumulation of 19 environmental phenolic and xenobiotic heterocyclic aromatic compounds in human adipose tissue. Environ. Int. 2015, 78, 45-50. [CrossRef]

19. Mínguez-Alarcón, L.; Gaskins, A.J. Female exposure to endocrine disrupting chemicals and fecundity: A review. Curr. Opin. Obstet. Gynecol. 2017, 29, 202-211. [CrossRef]

20. Weatherly, L.M.; Gosse, J.A. Triclosan exposure, transformation, and human health effects. J. Toxicol. Environ. Health Part B Crit. Rev. 2017, 20, 447-469. [CrossRef]

21. Government of Canada Chemical Products Safety-Triclosan. Available online: https://www.canada.ca/en/ health-canada/services/chemicals-product-safety/triclosan.html (accessed on 31 August 2020).

22. U.S. FDA 84 FR 14847-Safety and Effectiveness of Consumer Antiseptic Rubs; Topical Antimicrobial Drug Products for Over-the-Counter Human Use; Food and Drug Administration: Silver Spring, MD, USA, 2019; Volume 84, No. 71.

23. European Commission. Commission Implementing Decision (EU); European Commission: Luxembourg, 2016; Volume 2001, L 21/86.

24. Fernández-Castro, P.; San Román, M.F.; Ortiz, I. Theoretical and experimental formation of low chlorinated dibenzo-p-dioxins and dibenzofurans in the Fenton oxidation of chlorophenol solutions. Chemosphere 2016, 161, 136-144. [CrossRef] [PubMed]

25. Solá-Gutiérrez, C.; Schröder, S.; San Román, M.F.; Ortiz, I. PCDD/Fs traceability during triclosan electrochemical oxidation. J. Hazard. Mater. 2019, 369, 584-592. [CrossRef] [PubMed]

26. Vallejo, M.; Fernández-Castro, P.; San Román, M.F.; Ortiz, I. Assessment of PCDD/Fs formation in the Fenton oxidation of 2-chlorophenol: Influence of the iron dose applied. Chemosphere 2015, 137, 135-141. [CrossRef] [PubMed]

27. Vallejo, M.; San Román, M.F.; Ortiz, I.; Irabien, A. The critical role of the operating conditions on the fenton oxidation of 2-chlorophenol: Assessment of PCDD/Fs formation. J. Hazard. Mater. 2014, 279, 579-585. [CrossRef]

28. Vallejo, M.; San Román, M.F.; Ortiz, I. Quantitative assessment of the formation of polychlorinated derivatives, $\mathrm{PCDD} / \mathrm{Fs}$, in the electrochemical oxidation of 2-chlorophenol as function of the electrolyte type. Environ. Sci. Technol. 2013, 47, 12400-12408. [CrossRef]

29. Wold, A. Photocatalytic properties of $\mathrm{TiO}_{2}$. Chem. Mater. 1993, 5, 280-283. [CrossRef]

30. Ribao, P.; Corredor, J.; Rivero, M.J.; Ortiz, I. Role of reactive oxygen species on the activity of noble metal-doped $\mathrm{TiO}_{2}$ photocatalysts. J. Hazard. Mater. 2019, 372, 45-51. [CrossRef]

31. Ribao, P.; Rivero, M.J.; Ortiz, I. Enhanced photocatalytic activity using GO/TiO 2 catalyst for the removal of DCA solutions. Environ. Sci. Pollut. Res. 2018, 25, 34893-34902. [CrossRef]

32. Solá-Gutiérrez, C.; Schröder, S.; San-Román, M.F.; Ortiz, I. Critical review on the mechanistic photolytic and photocatalytic degradation of triclosan. J. Environ. Manag. 2020, 260, 110101. [CrossRef]

33. European Commission. Decision No 2455/2001/EC of the European Parliament and of the Council of 20 November 2001; European Commission: Luxembourg, 2004; Volume 2001.

34. U.S. EPA. 126 Priority Pollutants; U.S. EPA: Washington, DC, USA, 2012; Volume 29.

35. Constantin, L.A.; Nitoi, I.; Cristea, N.I.; Constantin, M.A. Possible degradation pathways of triclosan from aqueous systems via $\mathrm{TiO}_{2}$ assisted photocatalyis. J. Ind. Eng. Chem. 2018, 58, 155-162. [CrossRef]

36. Son, H.-S.; Ko, G.; Zoh, K.D. Kinetics and mechanism of photolysis and $\mathrm{TiO}_{2}$ photocatalysis of triclosan. J. Hazard. Mater. 2009, 166, 954-960. [CrossRef] [PubMed]

37. Stamatis, N.; Antonopoulou, M.; Hela, D.; Konstantinou, I. Photocatalytic degradation kinetics and mechanisms of antibacterial triclosan in aqueous $\mathrm{TiO}_{2}$ suspensions under simulated solar irradiation. J. Chem. Technol. Biotechnol. 2014, 89, 1145-1154. [CrossRef]

38. Bayarri, B.; Giménez, J.; Curcó, D.; Esplugas, S. Photocatalytic degradation of 2,4-dichlorophenol by TiO $2 / \mathrm{UV}$ Kinetics, actinometries and models. Catal. Today 2005, 101, 227-236. [CrossRef]

39. Yu, J.C.; Kwong, T.Y.; Luo, Q.; Cai, Z. Photocatalytic oxidation of triclosan. Chemosphere 2006, 65, 390-399. [CrossRef] [PubMed]

40. Zhang, H.; Huang, C.H. Oxidative transformation of triclosan and chlorophene by manganese oxides. Environ. Sci. Technol. 2003, 37, 2421-2430. [CrossRef] 
41. Sankoda, K.; Matsuo, H.; Ito, M.; Nomiyama, K.; Arizono, K.; Shinohara, R. Identification of triclosan intermediates produced by oxidative degradation using $\mathrm{TiO}_{2}$ in pure water and their endocrine disrupting activities. Bull. Environ. Contam. Toxicol. 2011, 86, 470-475. [CrossRef]

42. Rafqah, S.; Wong-Wah-Chung, P.; Nelieu, S.; Einhorn, J.; Sarakha, M. Phototransformation of triclosan in the presence of $\mathrm{TiO}_{2}$ in aqueous suspension: Mechanistic approach. Appl. Catal. B Environ. 2006, 66, 119-125. [CrossRef]

43. Ku, Y.; Hsieh, C.-B. Photocatalytic decomposition of 2,4-dichlorophenol in aqueous $\mathrm{TiO}_{2}$ suspensions. Water Res. 1992, 26, 1451-1456. [CrossRef]

44. Abeish, A.M.; Ang, H.M.; Znad, H. Solar photocatalytic degradation of chlorophenols mixture (4-CP and 2,4-DCP): Mechanism and kinetic modelling. J. Environ. Sci. Heal. Part A Toxic/Hazardous Subst. Environ. Eng. 2015, 50, 125-134. [CrossRef]

Publisher's Note: MDPI stays neutral with regard to jurisdictional claims in published maps and institutional affiliations.

(C) 2020 by the authors. Licensee MDPI, Basel, Switzerland. This article is an open access article distributed under the terms and conditions of the Creative Commons Attribution (CC BY) license (http://creativecommons.org/licenses/by/4.0/). 